\title{
Carbon Nanotubes-Hydroxyapatite Nanocomposites for an Improved Osteoblast Cell Response
}

\author{
Sabrina Constanda, ${ }^{1}$ Miruna Silvia Stan, ${ }^{1}$ Carmen Steluţa Ciobanu, ${ }^{2}$ \\ Mikael Motelica-Heino, ${ }^{3}$ Régis Guégan, ${ }^{3}$ \\ Khalid Lafdi, ${ }^{4}$ Anca Dinischiotu, ${ }^{1}$ and Daniela Predoi ${ }^{2}$ \\ ${ }^{1}$ Department of Biochemistry and Molecular Biology, Faculty of Biology, University of Bucharest, 91-95 Splaiul Independentei, \\ 050095 Bucharest, Romania \\ ${ }^{2}$ National Institute of Materials Physics, 105 Bis Atomistilor, 077125 Magurele, Romania \\ ${ }^{3}$ Institut des Sciences de la Terre d'Orléans (ISTO), UMR 7327 CNRS, Université d'Orléans, $1 \mathrm{~A}$ rue de la Férollerie, \\ 45071 Orléans Cedex 2, France \\ ${ }^{4}$ Chemical and Materials Engineering, University of Dayton Research Institute, 300 College Park, Dayton, OH 45469, USA
}

Correspondence should be addressed to Anca Dinischiotu; ancadinischiotu@yahoo.com and Daniela Predoi; dpredoi@gmail.com

Received 29 December 2015; Accepted 7 March 2016

Academic Editor: Victor M. Castaño

Copyright (C) 2016 Sabrina Constanda et al. This is an open access article distributed under the Creative Commons Attribution License, which permits unrestricted use, distribution, and reproduction in any medium, provided the original work is properly cited.

\begin{abstract}
An alternative and simple coprecipitation method was developed to obtain carbon nanotube-hydroxyapatite (CNTs:HAp) based nanocomposites. The incorporation of CNTs (in a concentration of $5 \%$ and $10 \%$ of total weight of the nanocomposite) and their impact on both structural and biological properties were studied by using a set of standard complementary biological, microscopic, and spectroscopic techniques. The characteristic peaks of carbon structure in CNTs were not observed in the CNTs-HAp composites by X-ray diffraction analysis. Moreover, FTIR and Raman spectroscopies confirmed the presence of HAp as the main phase of the synthesized CNTs:HAp nanocomposites. The addition of CNTs considerably affected the nanocomposite morphology by increasing the average crystallite size from $18.7 \mathrm{~nm}$ (for raw HAp) to $28.6 \mathrm{~nm}$ (for CNTs:HAp-10), confirming their proper incorporation. The biocompatibility evaluation of CNTs:HAp-5 and CNTs:HAp-10 nanocomposites included the assessment of several parameters, such as cell viability, antioxidant response, and lipid peroxidation, on human G-292 osteoblast cell line. Our findings revealed good biocompatibility properties for CNTs:HAp nanocomposites prepared by the coprecipitation method supporting their potential uses in orthopedics and prosthetics.
\end{abstract}

\section{Introduction}

One of the major problems that modern medicine has to face is the development of new materials that can mimic the human tissue in order to minimize the risk of rejection by the human body. According to a report of The American Association of Orthopedic Surgeons in 2002, bone implants are one of the most common transplants, outranked only by blood transfusions. In this context, worldwide, researchers have focused their attention on obtaining new and improved materials with special properties for hard tissue replacement implants. For this purpose, they explored the field of biomaterials. A study has revealed that, in a period of 6 years, between 2008 and 2014, the biomaterials device market has increased with almost 150 billion dollars $[1,2]$. There are two main categories of orthopedic biomaterials: implants usually made of metals, ceramics, or hard polymers and scaffolds for bone tissue regeneration [1]. The second type of biomaterials is based on biodegradable polymers and their composites [1]. The most frequently used biomaterial in orthopedic surgeries is hydroxyapatite (HAp). Having the chemical composition $\mathrm{Ca}_{10}\left(\mathrm{PO}_{4}\right)_{6}(\mathrm{OH})_{2}$, hydroxyapatite is found in human bones and teeth, being the main mineral constituent of natural hard tissue [3-5]. Given the similarity with the human tissue, synthetic hydroxyapatite can bond with natural bones [3]. Furthermore, it has outstanding properties, such as 
a remarkable bioactivity and osteoconductivity, which make it a suitable candidate for coating metallic implants, creating an adequate surface for bone growth and integration [1, 6-10]. However, recent studies have emphasized the weaknesses of HAp implants or coatings, caused by the fragility of synthetic hydroxyapatite, its low fracture toughness, wear resistance $[1,7-9,11,12]$, the appearance of corrosion, and negative tissue reaction. All these drawbacks can induce loosening of implants. Therefore, in order to improve the mechanical properties of HAp and to increase the corrosion resistance, its structure must be reinforced with materials such as carbon nanotubes (CNTs), $\mathrm{TiO}_{2}$, or $\mathrm{ZrO}_{2}$ [13-19]. Since the discovery of CNTs in 1991 by Iijima [20], they have been studied intensively due to their extraordinary thermal, electrical, and mechanical properties owed to their unique atomic structure [21-23]. Previous studies have proven that CNTs are some of the toughest materials discovered. Compared to steel, the tensile strength of carbon nanotubes is one hundred times higher, although the density is almost seven times lower than the density of steel $[24,25]$. Another remarkable property is the resistance of CNTs to erosion. They can withstand exposure to strong acids and alkali without having their structure affected [24, 26-28]. Moreover, the biocompatibility of CNTs in orthopedic applications by in vitro studies has been established, which showed an accelerated bone growth $[1,29]$. Also, several studies [1,30-33] have proven that carbon nanotubes induced increased proliferation and differentiation of osteoblasts in vitro. Although the biocompatibility of CNTs was not unanimously recognized due to the contradictory reports, it has been shown that different ceramics or polymer matrices reinforced with carbon nanotubes improve the structural properties, like fracture toughness, strength, elastic modulus, or wear resistance $[1,34-36]$ without jeopardizing the properties of the reinforced material.

In this study, we report the synthesis of CNTs:HAp nanocomposites at low temperature by a simple technique. The phase and the chemical structures of the prepared samples were tested by X-ray diffraction, Fourier transform infrared (FTIR), and Raman spectroscopies. Moreover, the structure of the CNTs:HAp-5 and CNTs:HAp-10 nanocomposites was analyzed by scanning electron microscopy (SEM). Furthermore, the human G-292 osteoblast-like cell line was selected as an in vitro model to assess CNTs:HAp nanotoxicity and biological properties. In order to test the biocompatibility of carbon nanotubes-hydroxyapatite based nanocomposites, several parameters including cell viability, antioxidant response, and lipid peroxidation were assessed.

\section{Materials and Methods}

2.1. Chemicals. The reagents used for the synthesis of hydroxyapatite were ammonium dihydrogen phosphate $\left[\left(\mathrm{NH}_{4}\right)_{2} \mathrm{HPO}_{4}\right]$ (Alpha Aesare, Germany, 99.99\% purity), calcium nitrate $\left[\mathrm{Ca}\left(\mathrm{NO}_{3}\right)_{2} \cdot 4 \mathrm{H}_{2} \mathrm{O}\right]$ (Alpha Aesare, Germany, 99.99\% purity), and ammonium hydroxide $\left[\mathrm{NH}_{4} \mathrm{OH}\right]$ (Alpha Aesare, Germany, 99.99\% purity).

2.2. Preparation of Carbon Nanotubes. The chemical vapor deposition (CVD) method was used to grow single-wall
CNTs onto a quartz substrate. The CVD method synthesis is essentially a two-step process consisting of a catalyst preparation step followed by the actual synthesis of the CNTs. The quartz piece cut into required dimensions was first heat treated in a furnace at $500^{\circ} \mathrm{C}$ for about 10 minutes. It was then cooled down to the room temperature and dipped in the catalyst that was basically a solution of ethanol and FeMo in mole ratio of $10: 1$. The quartz substrate thus dipped in catalyst was then placed in a quartz tube in a CVD furnace. The deposited Fe catalyst was then reduced at $800^{\circ} \mathrm{C}$ by using hydrogen and argon gases which passed through the furnace. Finally, the substrate was subjected to a source of carbon by the passing of ethylene gas that caused the decomposition of carbon and resulted in the synthesis of CNTs.

\subsection{Preparation of Hydroxyapatite-Carbon Nanotube Com-} posite. The synthesis of carbon nanotubes-hydroxyapatite (CNTs:HAp) nanocomposites was achieved by an adapted coprecipitation method. $\mathrm{Ca}\left(\mathrm{NO}_{3}\right)_{2} \cdot 4 \mathrm{H}_{2} \mathrm{O}$ was dissolved in $300 \mathrm{~mL}$ deionized water. Then, a quantity of $0.5 \mathrm{~g}$ or $1 \mathrm{~g}$ of CNTs was added into the $\mathrm{Ca}\left(\mathrm{NO}_{3}\right)_{2} \cdot 4 \mathrm{H}_{2} \mathrm{O}$ solution and was sonicated for 12 hours to obtain a homogeneous mixture. On the other hand, the $\left(\mathrm{NH}_{4}\right)_{2} \mathrm{HPO}_{4}$ was dissolved in $300 \mathrm{~mL}$ deionized water according to the molar ratio of $\mathrm{Ca} / \mathrm{P} 1: 67$. The $\left(\mathrm{NH}_{4}\right)_{2} \mathrm{HPO}_{4}$ solution was added drop by drop into the $\left[\mathrm{CNTs}+\mathrm{Ca}\left(\mathrm{NO}_{3}\right)_{2} \cdot 4 \mathrm{H}_{2} \mathrm{O}\right]$ homogeneous mixture with continuous stirring at $50^{\circ} \mathrm{C}$ for 12 hours. The $\mathrm{pH}$ was constantly adjusted and kept at 10 with ammonia solution during the reaction. The resulting mixture was washed several times with deionized water maintaining a neutral $\mathrm{pH}$ to remove the residual $\mathrm{NO}_{3}{ }^{-}$and $\mathrm{NH}_{4}{ }^{+}$. The resulting CNTs:HAp-5 $\left(0.5 \mathrm{~g}\right.$ of CNTs added into the $\mathrm{Ca}\left(\mathrm{NO}_{3}\right)_{2} \cdot 4 \mathrm{H}_{2} \mathrm{O}$ solution) and CNTs:HAp-10 (1 g of CNTs added into the $\mathrm{Ca}\left(\mathrm{NO}_{3}\right)_{2} \cdot 4 \mathrm{H}_{2} \mathrm{O}$ solution) nanocomposite samples were dried at $80^{\circ} \mathrm{C}$ for 48 hours in an oven. Furthermore, the synthesis of hydroxyapatite (HAp; $\left.\mathrm{Ca}_{10}\left(\mathrm{PO}_{4}\right)_{6}(\mathrm{OH})_{2}\right)$ was carried out as reported $[37,38]$ by the following reaction [39]:

$$
\begin{array}{r}
10 \mathrm{Ca}\left(\mathrm{NO}_{3}\right)_{2} \cdot 4 \mathrm{H}_{2} \mathrm{O}+6\left(\mathrm{NH}_{4}\right)_{2} \mathrm{HPO}_{4}+2 \mathrm{NH}_{4} \mathrm{OH} \\
\longrightarrow \mathrm{Ca}_{10}\left(\mathrm{PO}_{4}\right)_{6}(\mathrm{OH})_{2}+20 \mathrm{NH}_{4} \mathrm{NO}_{3}+46 \mathrm{H}_{2} \mathrm{O}
\end{array}
$$

2.4. Sample Characterization. X-ray diffraction characterization was carried out using a Bruker D8 Advance diffractometer, with nickel filtered $\mathrm{CuK}_{\alpha}(\lambda=1.5418 \AA)$ radiation with a high efficiency one-dimensional detector (Lynx Eye type) operated in integration mode. The diffraction patterns were collected in the $2 \theta$ range $20^{\circ}-90^{\circ}$, with a step of $0.02^{\circ}$ and 34 seconds measuring time per step. A Perkin Elmer 1720X FTIR spectrometer was used for all spectroscopic studies. The instrument was equipped with a horizontal ATRFTIR accessory from Spectra-Tech. All the spectra were the results of 256 coadded scans at a resolution of $4 \mathrm{~cm}^{-1}$ and a spectral range of $500-2000 \mathrm{~cm}^{-1}$. All of the FTIR analyses were conducted at room temperature around $23^{\circ} \mathrm{C}$. The spectrum was recorded in the range of 500 to $4000 \mathrm{~cm}^{-1}$ with $4 \mathrm{~cm}^{-1}$ resolution. Micro-Raman spectra on powders were performed in a backscattering geometry at room temperature and in ambient air, under a laser excitation wavelength of 
514 nm, using a Jobin Yvon T64000 Raman spectrophotometer placed under a microscope. The morphology of the HAp, NTCs, NTCs:HAp-5, and NTCs:HAp-10 was analyzed by SEM (HITACHI S2600N microscope).

2.5. Cell Culture and Treatment. G-292 osteoblast cell line (ATCC CRL-1423) derived from human osteosarcoma was cultured in McCoy's 5A medium (Gibco, USA) supplemented with $1.5 \mathrm{mM}$ L-glutamine, $2.2 \mathrm{~g} / \mathrm{L}$ sodium bicarbonate, penicillin $(100 \mathrm{U} / \mathrm{mL})$, streptomycin $(100 \mu \mathrm{g} / \mathrm{mL})$, and $10 \%$ fetal bovine serum (Gibco, USA). Cells were grown in $25 \mathrm{~cm}^{2}$ flasks and incubated at $37^{\circ} \mathrm{C}$ in a humidified atmosphere with $5 \% \mathrm{CO}_{2}$, while the medium was replaced every 2 to 3 days. Cells were detached for subcultivation using 0.25\% trypsin$0.53 \mathrm{mM}$ EDTA solution. The osteoblasts were counted and distributed at a density of $2 \times 10^{4}$ cells $/ \mathrm{cm}^{2}$ into 96 -well plates or $25 \mathrm{~cm}^{2}$ flasks and incubated at $37^{\circ} \mathrm{C}$ in a humidified atmosphere with $5 \% \mathrm{CO}_{2}$ to allow cell adhesion overnight. Afterwards, cells were exposed to various concentrations $(0.25,2.5,25,100$, and $500 \mu \mathrm{g} / \mathrm{mL})$ of CNTs, HAp, CNTs:HAp5, and CNTs:HAp-10 for 24 and 48 hours.

2.6. MTT Assay. Cell viability was evaluated by MTT (3-(4,5dimethylthiazol-2-yl)-2,5-diphenyltetrazolium bromide) colorimetric assay. After 24 and 48 hours of exposure to CNTs, HAp, and CNTs:HAp-5 and CNTs:HAp-10 nanocomposites, the medium was removed and the cells were washed with PBS and incubated with $1 \mathrm{mg} / \mathrm{mL}$ MTT solution for 2 hours at $37^{\circ} \mathrm{C}$. Afterwards, the MTT solution was removed and the purple intracellular formazan crystals were solubilized with isopropanol. The absorbance was read at $595 \mathrm{~nm}$ using a Tecan multiplate reader (TECAN GENios, Grödic, Germany) and the optical density for untreated cells was represented as a viability of $100 \%$. In spite of all controversies in using the MTT assay to test cytotoxicity of CNTs and to determine relative cell viability, we did not observe any interference of CNTs with the MTT assay, or any indication of false results, which is supported by previous studies on CNTs $[40,41]$.

2.7. Glutathione Assay. At the end of exposure, cells were detached and total protein extract was obtained by sonication ( 3 times $\times 30$ seconds on ice) using an ultrasonic processor (Hielscher UP50H, Germany). The cell lysate was further deproteinized with a $5 \%$ sulfosalicylic acid $(1: 1)$, centrifuged at $10,000 \mathrm{rpm}$ for 10 minute at $4^{\circ} \mathrm{C}$. The cellular GSH concentration was determined using the Glutathione Assay Kit (Sigma-Aldrich, USA) following the protocol provided by the manufacturer. Briefly, each sample was incubated with 5,5'-dithiobis-2-nitrobenzoic acid (DTNB) for 5 minutes at room temperature in order to allow the reduction of DTNB into 5-thio-2-nitrobenzoic acid (TNB). The absorption was recorded at $405 \mathrm{~nm}$ using a Tecan multiplate reader (TECAN GENios, Grödic, Germany). The GSH levels were calculated as nmoles GSH/mg protein and the results were expressed relative to control.

2.8. Malondialdehyde Assay. Malondialdehyde (MDA) concentration was assessed according to the method described by Dinischiotu et al. [42]. A volume of $200 \mu \mathrm{L}$ of sample diluted correspondingly was mixed with $700 \mu \mathrm{L}$ of $0.1 \mathrm{~N} \mathrm{HCl}$ and incubated for 20 minutes at room temperature. Then, $900 \mu \mathrm{L}$ of $0.025 \mathrm{M}$ thiobarbituric acid (TBA) was added and the total mixture was incubated for $65 \mathrm{~min}$ at $37^{\circ} \mathrm{C}$. The MDATBA adduct fluorescence was measured using a JASCO FP6300 spectrofluorometer $\left(\lambda_{\text {ex }} / \lambda_{\text {em }}\right.$ of $\left.520 \mathrm{~nm} / 549 \mathrm{~nm}\right)$. The MDA concentration was calculated using a standard curve of $1,1,3,3$-tetramethoxypropane in the range of $0.05-5 \mu \mathrm{M}$ and expressed as nmoles of $\mathrm{MDA} / \mathrm{mg}$ protein. The results were represented relative to control.

2.9. Protein Concentration Assay. The protein concentration of the cellular extract was determined by Bradford method [43] using bovine serum albumin as standard.

2.10. Statistical Analysis. All values are expressed as mean value \pm standard deviation (SD) of three independent experiments. The data was analyzed for statistical difference by Student's $t$-test. A $p$ value less than 0.05 was considered significant.

\section{Results and Discussion}

3.1. Characterization of Carbon Nanotubes and Hydroxyapatite Composite Materials. X-ray diffraction patterns of pure HAp and CNTs:HAp (CNTs:HAp-5 and CNTs:HAp10) nanocomposites in the $2 \theta$ ranges $20^{\circ}-90^{\circ}$ and $20^{\circ}-$ $30^{\circ}$, respectively, are shown in Figure 1 . The characteristic diffraction pattern of CNTs:HAp-5 and CNTs:HAp-10 nanocomposites shows a similar behavior of the spectrum for pure HAp (Figure 1(b)). The peak observed at $2 \theta=$ $26.38^{\circ}$, characteristic to CNTs, made no contribution to the specific peak of hydroxyapatite $\left(2 \theta=25.84^{\circ}\right)$, which shows that the peaks corresponding to the addition of CNTs did not appear. It can also be seen that the diffraction peaks of CNTs:HAp composites are in agreement with those of pure HAp indexed to the hexagonal $\mathrm{Ca}_{10}\left(\mathrm{PO}_{4}\right)_{6}(\mathrm{OH})_{2}$ in $P_{63 \mathrm{~m}}$ space group (ICDD-PDF number 9-432).

The average sizes $D$ of HAp and CNTs:HAp were calculated from the XRD patterns using Scherrer's formula [44]: $D=K \lambda / B \cos \theta$, where $K$ is a constant (shape-factor) whose value is $0.9, \lambda$ is the wavelength of $\mathrm{X}$-rays (1.5406 $\AA$ ), $B$ (in $\mathrm{rad}$ ) is the full width at half maximum (FWHM), and $\theta$ is the Bragg angle. The grain size increased from $18.7 \pm 1 \mathrm{~nm}$ (HAp) to $22.5 \pm 1 \mathrm{~nm}$ (CNTs:HAp-5) and to $28.6 \pm 1 \mathrm{~nm}$ (CNTs:HAp10).

In good agreement with previous studies [45], the XRD patterns of HAp and CNTs:HAp composites demonstrate that the powders exhibit the apatite characteristics with good crystal structure and no new phase or impurity was found.

The phase and the chemical structures of the CNTs:HAp nanocomposite were analyzed by FTIR and Raman spectroscopies. The ATR-FTIR technique was used to investigate the CNTs:HAp nanocomposites. Figure 2 shows the ATRFTIR spectra of pure HAp, CNTs:HAp-5, and CNTs:HAp10 nanocomposites. It has been reported that the vibration peaks at $1645 \mathrm{~cm}^{-1}$ correspond to $\mathrm{H}-\mathrm{O}-\mathrm{H}$ bands of water lattice [37]. The band at $630 \mathrm{~cm}^{-1}$ characteristic to 


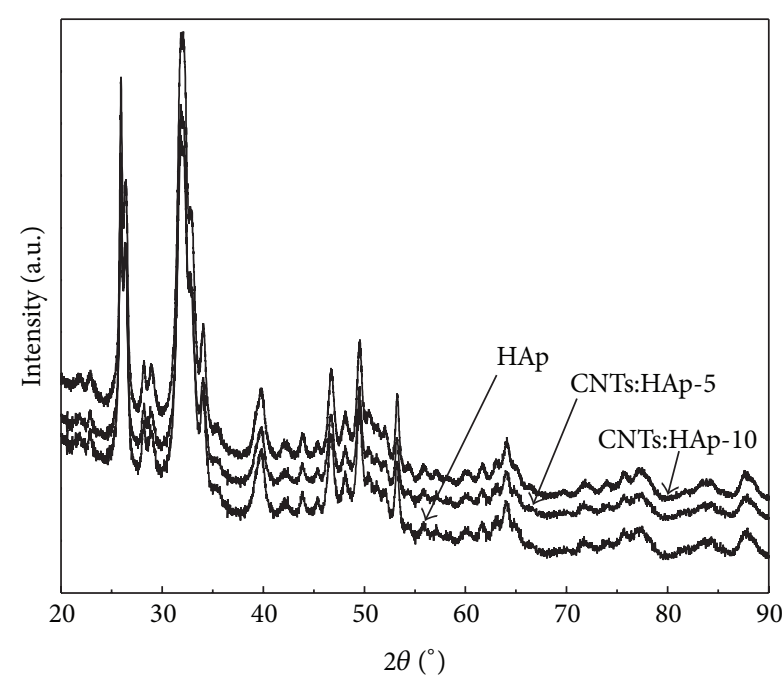

(a)

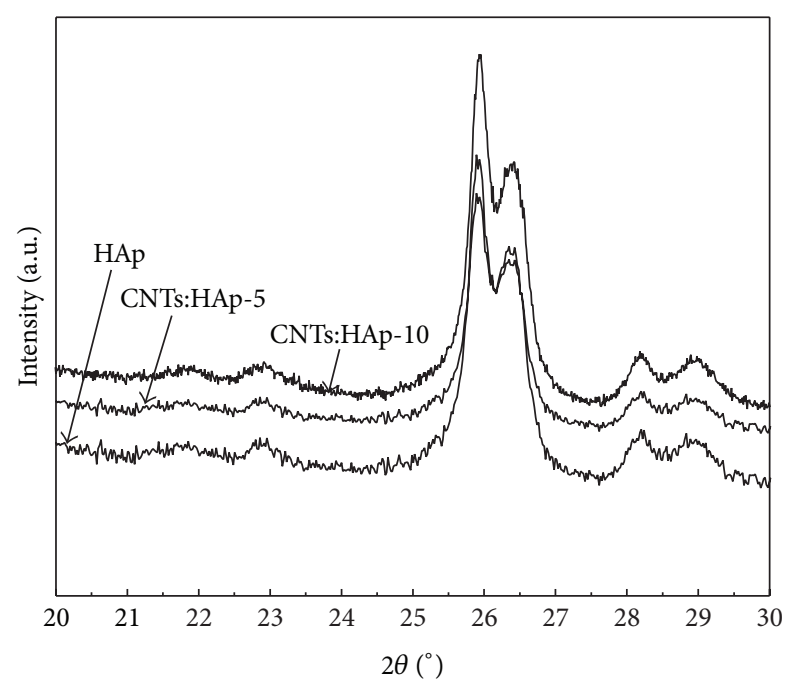

(b)

FIGURE 1: Comparative representation of the experimental XRD patterns of the HAp and CNTs:HAp-5 and CNTs:HAp-10 nanocomposites in the $2 \theta$ ranges $20^{\circ}-90^{\circ}$ (a) and $20^{\circ}-30^{\circ}$ (b), respectively.
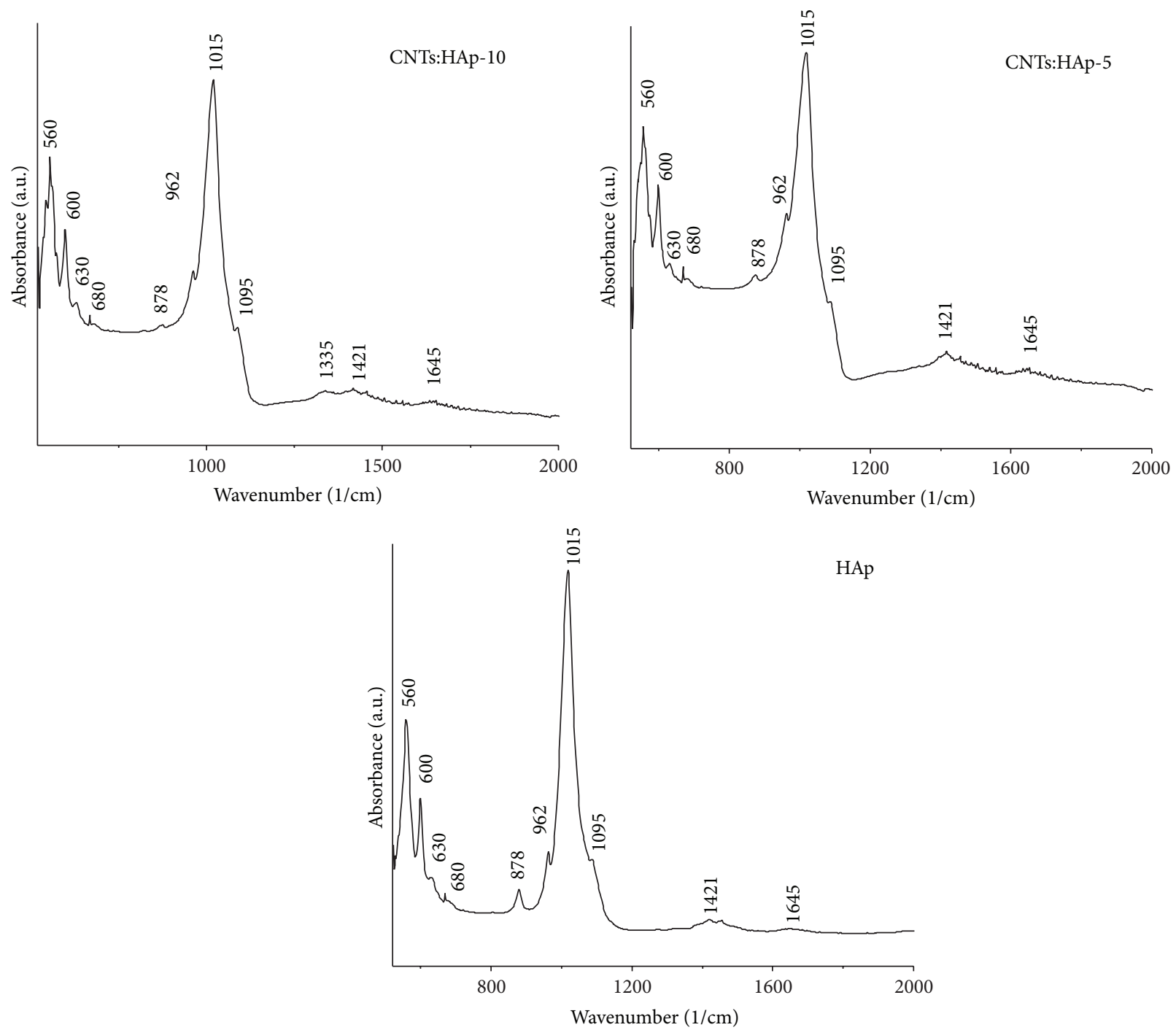

FiguRE 2: FTIR-ATR spectra of the pure HAp and CNTs:HAp-5 and CNTs:HAp-10 nanocomposites. 

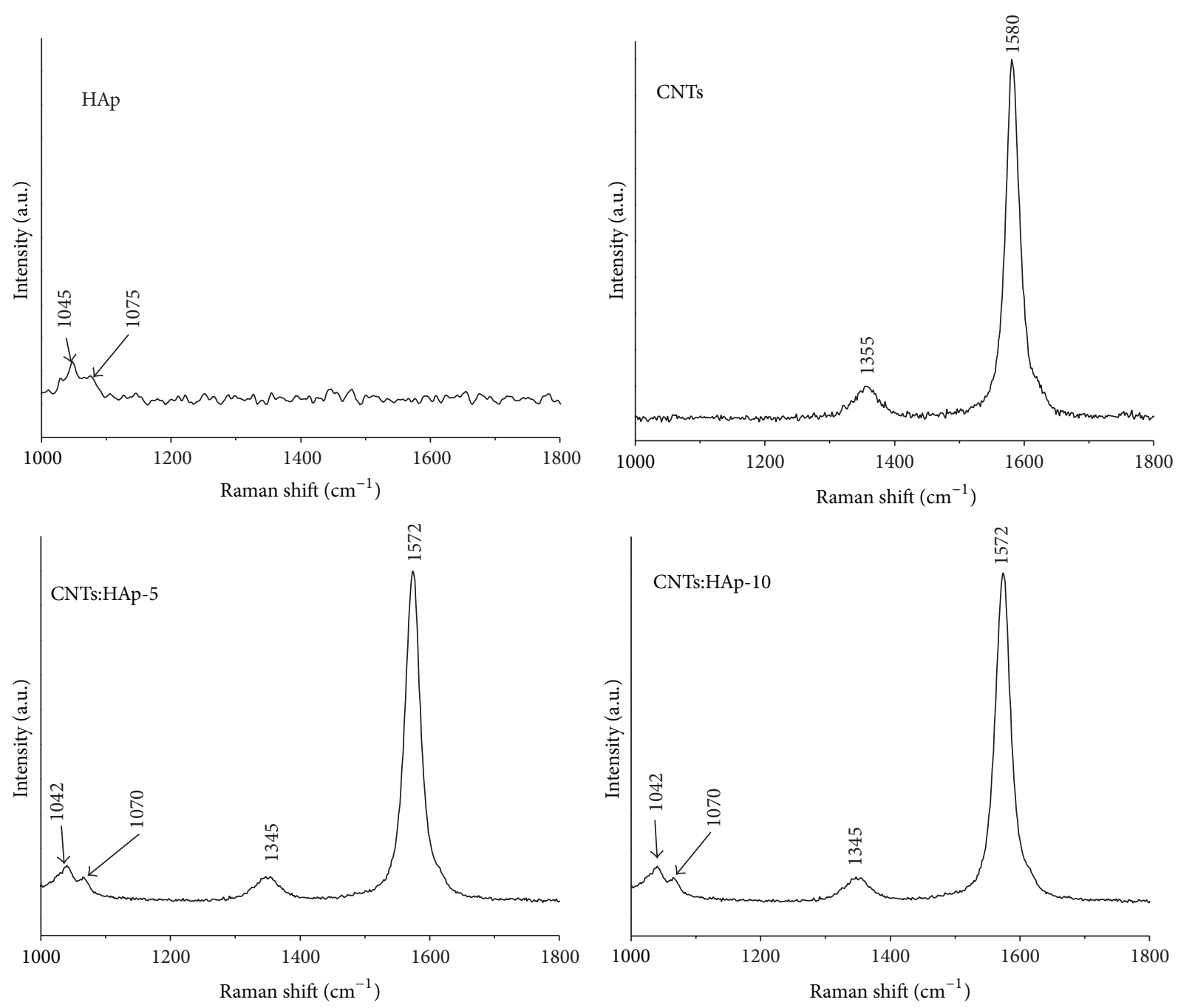

Figure 3: Raman spectra of HAp, CNTs, and CNTs:HAp-5 and CNTs:HAp-10 nanocomposites.

the stretching vibrational mode of $[\mathrm{OH}]^{-}$was present in both HAp and CNTs:HAp (CNTs:HAp-5 and CNTs:HAp10) composites spectra and indicated a well-crystallized HAp $[46,47]$. According to previous studies conducted by Yang et al. [48] and Pan et al. [49], the band at $1095 \mathrm{~cm}^{-1}$ suggests also the formation of a well-crystallized apatite.

On the other hand, the bands at $600 \mathrm{~cm}^{-1}$ and $560 \mathrm{~cm}^{-1}$ appearing from $v_{4}\left[\mathrm{PO}_{4}\right]^{3-}$ and indicated also a wellcrystallized HAp [47]. The band at $962 \mathrm{~cm}^{-1}$ is due to $v_{1}$ $\left[\mathrm{PO}_{4}\right]^{3-}$ mode of phosphates while the bands at $1015 \mathrm{~cm}^{-1}$ and $1095 \mathrm{~cm}^{-1}$ can be attributed to the $v_{3}\left[\mathrm{PO}_{4}\right]^{3-}$ mode of phosphates [50, 51]. According to Ciobanu et al. [37, 46], the characteristic bands for carbonate at 878 and $1421 \mathrm{~cm}^{-1}$ are probably due to the combination of $v_{2}$-out-of-plane bend vibration and $v_{3}$-asymmetric stretching vibration. In the ATR-FTIR spectra, the bands of phosphates and the carbonate were observed for all samples. The characteristic peak of CNTs at $2359 \mathrm{~cm}^{-1}$ reported in literature by Niu et al. [52] was not observed in the CNTs:HAp nanocomposites. On the other hand, the bands around $2919 \mathrm{~cm}^{-1}$ and $2852 \mathrm{~cm}^{-1}$ which are due to the asymmetric and symmetric stretching of $\mathrm{C}-\mathrm{H}$ bonds reported by Krishna Kumar et al. [53] were not observed in the NTCs:HAp nanocomposites spectra. The FTIR spectra of CNTs:HAp-5 and CNTs:HAp-10 nanocomposites exhibited similar peaks to those of pure HAp except for the peak at $1335 \mathrm{~cm}^{-1}$ which appeared in CNTs:HAp-10 nanocomposites spectrum. According to Wahab et al. [54] the peak at around $1335 \mathrm{~cm}^{-1}$ is characteristic to the vibrational mode of carbonate ions in hydroxyl sites. Following these investigations, we can say that the presence of CNTs in the CNTs:HAp nanocomposites does not change the basic structure of HAp.

The proper formation of CNTs:HAp nanocomposites was confirmed through Raman scattering. Figure 3 shows the Raman spectra of HAp, CNTs, CNTs:HAp-5, and CNTs:HAp10 composites.

The vibrational bands attributed to asymmetric $v_{3}(\mathrm{P}-\mathrm{O})$ stretching [37] are observed at the wavenumbers of $1045 \mathrm{~cm}^{-1}$ $\left(v_{3}\right)$ and $1075 \mathrm{~cm}^{-1}\left(v_{3}\right)$ for raw HAp while they shift to lower wavenumber at $1042 \mathrm{~cm}^{-1}\left(v_{3}\right)$ and $1070 \mathrm{~cm}^{-1}\left(v_{3}\right)$ for CNTs:HAp-5 and CNTs:HAp-10 nanocomposites, respectively. The proper incorporation of CNTs was confirmed by 


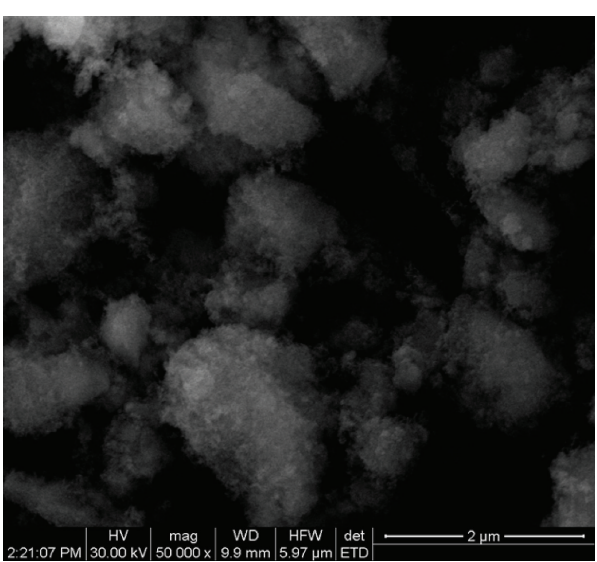

(a)

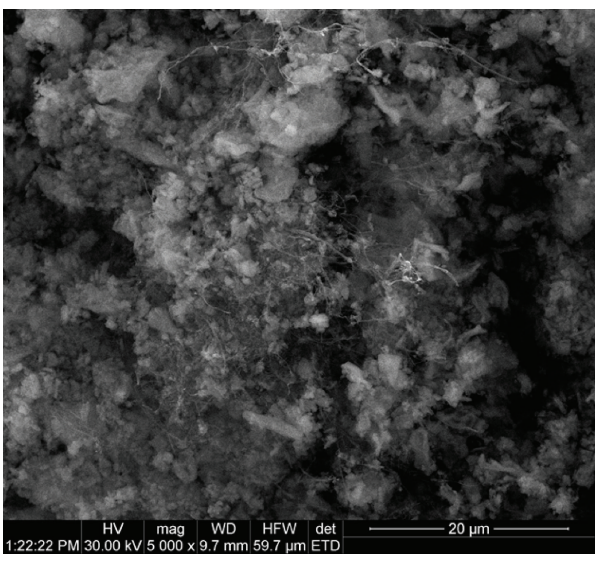

(c)

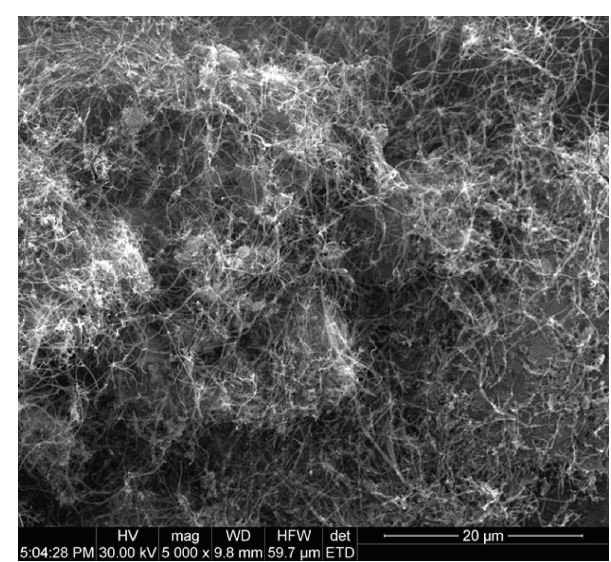

(b)

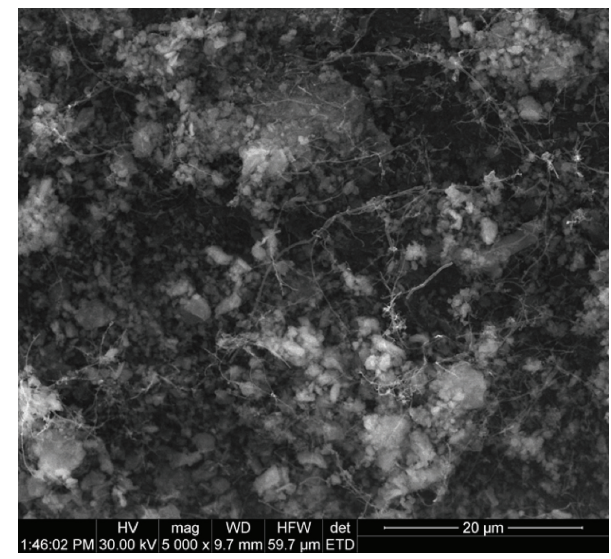

(d)

Figure 4: SEM images of pure HAp (a), CNTs (b), and CNTs:HAp-5 (c) and CNTs:HAp-10 (d) nanocomposites.

the presence of two common bands, in the region 1300$1600 \mathrm{~cm}^{-1}$ for both the CNTs:HAp-5 and CNTs:HAp-10 spectra, related to the D and G bands. For bulk CNTs, these bands that underline the degree of crystallinity and order in the graphitization process appear at $1345 \mathrm{~cm}^{-1}$ and $1572 \mathrm{~cm}^{-1}$. Once CNTs were mixed with HAp, these bands shifted to lower frequencies at $1355 \mathrm{~cm}^{-1}$ and $1580 \mathrm{~cm}^{-1}$ for the $\mathrm{D}$ and G bands, respectively. Previous studies [55-57] showed that the peaks at $1580 \mathrm{~cm}^{-1}$ (in CNTs spectrum) and $1575 \mathrm{~cm}^{-1}$ (in CNTs:HAp-5 and CNTs:HAp-10 nanocomposites spectra) were associated with the tangential displacement of $\mathrm{C}-\mathrm{C}$ band stretching mode of the well-graphitized nanotubes. On the other hand, the peaks at $1355 \mathrm{~cm}^{-1}$ (in CNTs spectra) and $1345 \mathrm{~cm}^{-1}$ (in CNTs:HAp-5 and CNTs:HAp-10 nanocomposite spectra) were associated with the vibration of carbon atoms in the disorder mode. Comparing the D-mode and G-mode of CNTs and CNTs:HAp-5 and CNTs:HAp-10 nanocomposites, a little change in the frequency value was observed which can be associated with an increase in the defect density of graphite after being mixed into HAp [58].

The nanostructure and morphology of pure HAp, CNTs, and CNTs:HAp-5 and CNTs:HAp-10 nanocomposites were studied by SEM (Figure 4). The SEM images of CNTs:HAp5 and CNTs:HAp-10 revealed that the nanoparticles were uniformly distributed without forming any agglomeration. The CNTs packages have been destroyed as a result of the formation of CNTs:HAp nanocomposite.

In previous studies, Zheng et al. [59] showed that the CNTs tended to aggregate in water due to the van der Waals interactions. Compared to pure and nonfunctionalized CNTs samples presented in Figure 4, the CNTs:HAp nanocomposite could be dispersed well due to the presence of HAp.

3.2. Biochemical Studies. As it can be observed from Figure 5(a), a dose-dependent decrease in cell viability was registered for CNTs treated cells after 24 hours of exposure, whereas HAp stimulated cell proliferation confirming its biocompatibility effect. At the same time, the cell viability for low doses of CNTs:HAp- 5 was not significantly changed (only a $10 \%$ decrease for $25 \mu \mathrm{g} / \mathrm{mL}$ compared with control). Regarding the highest doses $(100 \mu \mathrm{g} / \mathrm{mL}$ and $500 \mu \mathrm{g} / \mathrm{mL}$ CNTs:HAp5), the viability was diminished by $17 \%$ and $20 \%$, respectively, compared to the control. Exposure to CNTs:HAp-10 induced a decreased viability only for doses higher than $2.5 \mu \mathrm{g} / \mathrm{mL}$ (a $28 \%$ decrease for the concentration of $500 \mu \mathrm{g} / \mathrm{mL}$ compared to control).

Further, our results (Figure 5(b)) showed that CNTs exhibited a higher cytotoxicity after 48-hour exposure 


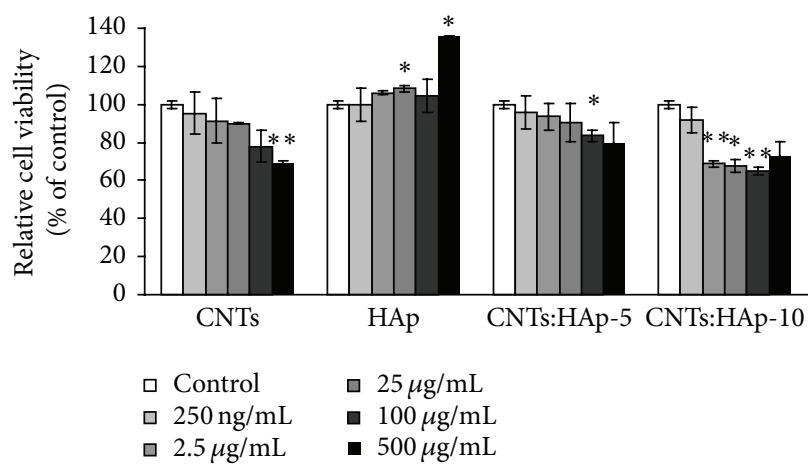

(a)

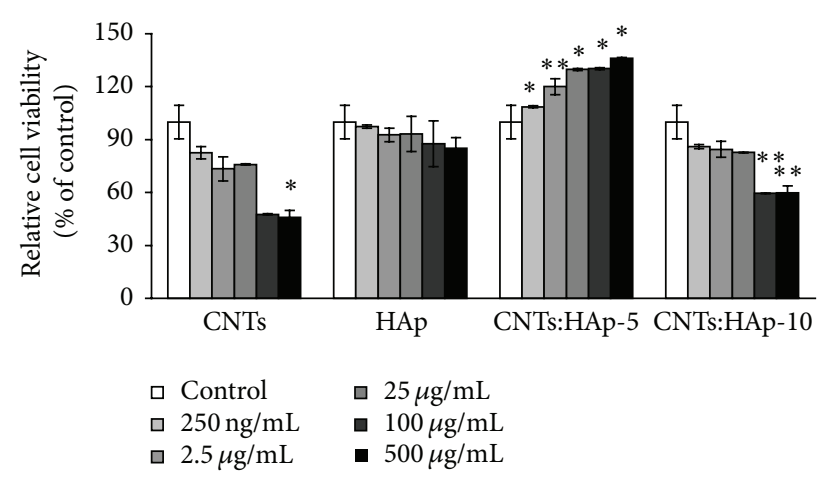

(b)

Figure 5: Cell viability after 24 (a) and 48 (b) hours of exposure to NTCs, HAp, and CNTs:HAp-5 and CNTs:HAp-10. Values are calculated as means $\pm \operatorname{SD}(n=3)$ and expressed relative to control. ${ }^{*} p<0.05$ and ${ }^{* *} p<0.01$ versus control.

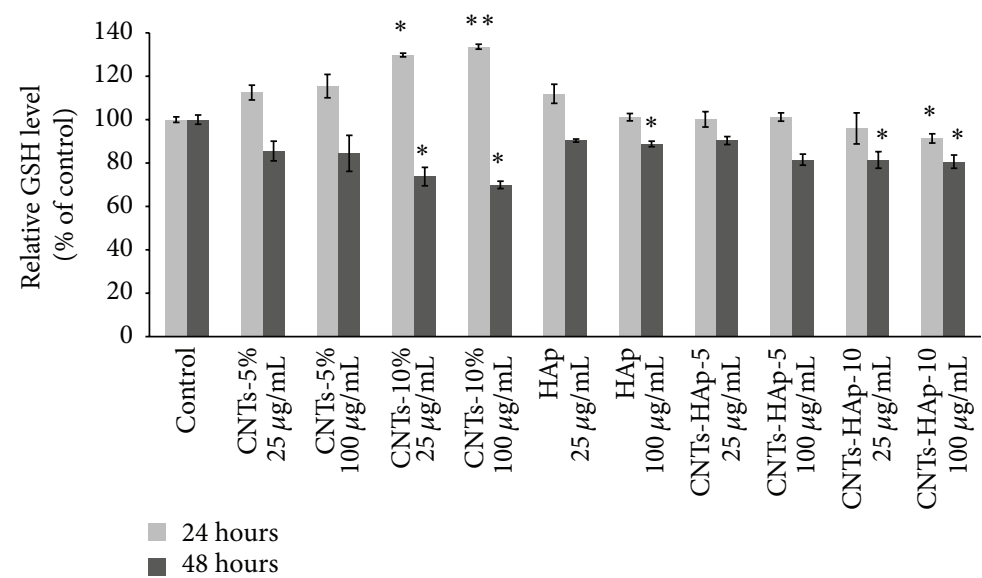

FIGURE 6: GSH levels in G-292 cells exposed to CNT, HAp, and CNTs:HAp-5 and CNTs:HAp-10 at concentrations of $25 \mu \mathrm{g} / \mathrm{mL}$ and $100 \mu \mathrm{g} / \mathrm{mL}$ for 24 and 48 hours. Values are calculated as means $\pm \mathrm{SD}(n=3)$ and expressed relative to control. ${ }^{*} p<0.05$ and ${ }^{* *} p<0.01$ versus control.

compared to 24-hour one and the cell viability was slightly decreased compared to control after the incubation with HAp. CNTs:HAp-5 nanocomposites stimulated cell proliferation in a dose-dependent manner suggesting a higher biocompatibility compared with CNTs:HAp-10 nanocomposites which were more toxic at higher doses $(100 \mu \mathrm{g} / \mathrm{mL}$ and $500 \mu \mathrm{g} / \mathrm{mL}$ ). The significant increase of cell viability for CNTs:HAp- 5 after 48 hours could be explained by the fact that there is a time interval necessary for osteoblasts to adapt to the environment created by the nanocomposites.

Humans are well equipped with an excellent antioxidant system to fight against oxidative stress induced by a various number of damaging effects, protecting efficiently against the formation of free radicals. Thus, being the most prevalent endogenous intracellular thiol antioxidant, GSH plays a central role in neutralizing free radicals and reactive oxygen species.

After 24 hours, a dose-dependent increase of GSH level was noticed in the cells exposed to simple CNTs, whereas a decrease was observed at 48 hours of treatment, suggesting the CNTs toxicity (Figure 6). Regarding the incubation with CNTs:HAp nanocomposites, the GSH content was near to the control values and HAp levels after the first 24 hours diminished only by $20 \%$ compared with control for the highest dose, proving their biocompatibility. The above results are similar to the studies performed by Patel and Kwon [60], in which higher GSH levels were observed after 24 hours of treatment and lower values after 48 hour exposure of A549 epithelial cells to multiwalled carbon nanotubes (MWCNTs). The initial increase could be due to a higher demand of GSH to combat the rapid formation of reactive oxygen species (ROS), followed by the depletion of this tripeptide that was rapidly consumed in the resulted oxidative stress.

The level of MDA was determined as a marker of lipid peroxidation in G-292 cells exposed to 25 and $100 \mu \mathrm{g} / \mathrm{mL}$ of CNTs, HAp, CNTs:HAp-5, and CNTs:HAp-10 (Figure 7).

After both time intervals of incubation with simple CNTs or CNTs:HAp nanocomposites, MDA contents increased in a dose- and time-dependent manner compared with the control, but the peroxidation for nanocomposites was below the CNTs level. Thus, the nanocomposites showed a lower toxicity compared to CNTs, suggesting their biocompatibility on human osteoblasts through the presence of HAp. In the case of pure HAp exposure, the MDA levels were near the control values, suggesting the absence of hydroxyapatite toxicity. In addition, the oxidative stress induced by CNTs 


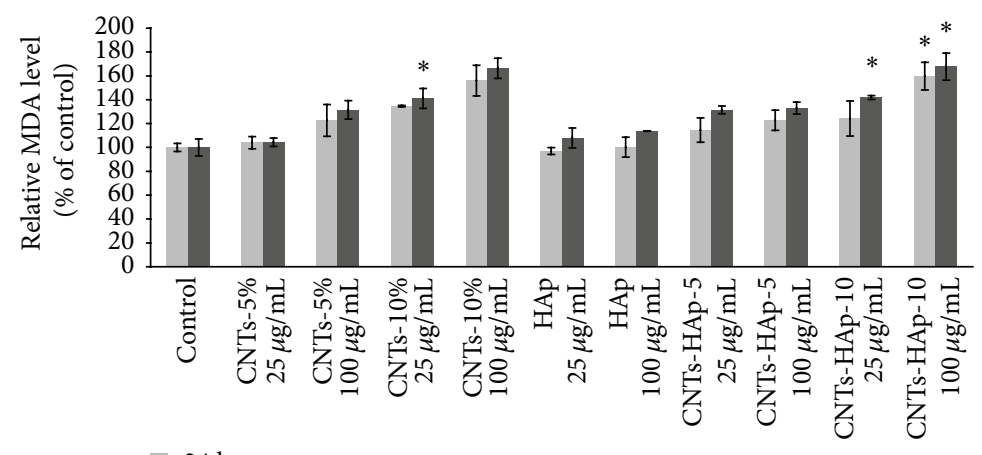

$$
\begin{array}{r}
24 \text { hours } \\
\text { - } 48 \text { hours }
\end{array}
$$

Figure 7: MDA levels in G-292 cells exposed to CNTs, HAp, and CNTs:HAp-5 and CNTs:HAp-10 at concentrations of $25 \mu \mathrm{g} / \mathrm{mL}$ and $100 \mu \mathrm{g} / \mathrm{mL}$ for 24 and 48 hours. Values are calculated as means \pm SD $(n=3)$ and expressed relative to control. ${ }^{*} p<0.05$ versus control.

correlated very well with the decreased cell viability observed in Figure 5.

\section{Conclusions}

In this study, we obtained CNTs:HAp nanocomposites through a simple adapted coprecipitation method, which was followed by a characterization of chemical, structural, and biological properties in order to establish their biocompatibility on human osteoblasts. XRD analysis results revealed a good crystal structure, without any peaks corresponding to the addition of CNTs or impurities. Comparing the D-mode and G-mode of CNTs and CNTs:HAp composites, a minor change in the frequency value was observed. All biochemical parameters investigated with the help of in vitro methods presented a variation dependent on time and concentration. Taken together, low doses of CNTs doped hydroxyapatite nanocrystalline powders did not significantly decrease G-292 cell viability and did not induce oxidative stress after 2 days of exposure. These results support the applicability of CNT:HAp nanocomposites prepared by the coprecipitation method for medical purposes because they exhibit good biocompatibility and have great potential in the future for orthopedics and prosthetics.

\section{Competing Interests}

The authors declare that there are no competing interests regarding the publication of this paper.

\section{Authors' Contributions}

Sabrina Constanda and Miruna Silvia Stan contributed equally to this work.

\section{Acknowledgments}

The financial and encouragement support was provided by the strategic Grant POSDRU/159/1.5/S/133391 cofinanced by the European Social Fund.

\section{References}

[1] D. Lahiri, S. Ghosh, and A. Agarwal, "Carbon nanotube reinforced hydroxyapatite composite for orthopedic application: a review," Materials Science and Engineering C, vol. 32, no. 7, pp. 1727-1758, 2012.

[2] F. Moussy, "Biomaterials for the developing world," Journal of Biomedical Materials Research Part A, vol. 94, no. 4, pp. 10011003, 2010.

[3] M. Šupová, "Substituted hydroxyapatites for biomedical applications: a review," Ceramics International, vol. 41, no. 8, Article ID 10395, pp. 9203-9231, 2015.

[4] W. Suchanek and M. Yoshimura, "Processing and properties of hydroxyapatite-based biomaterials for use as hard tissue replacement implants," Journal of Materials Research, vol. 13, no. 1, pp. 94-117, 1998.

[5] D. Tadic, F. Peters, and M. Epple, "Continuous synthesis of amorphous carbonated apatites," Biomaterials, vol. 23, no. 12, pp. 2553-2559, 2002.

[6] Y. W. Gu, N. H. Loh, K. A. Khor, S. B. Tor, and P. Cheang, "Spark plasma sintering of hydroxyapatite powders," Biomaterials, vol. 23, no. 1, pp. 37-43, 2002.

[7] A. A. White, S. M. Best, and I. A. Kinloch, "Hydroxyapatitecarbon nanotube composites for biomedical applications: a review," International Journal of Applied Ceramic Technology, vol. 4, no. 1, pp. 1-13, 2007.

[8] L.-G. Yu, K. A. Khor, H. Li, and P. Cheang, "Effect of spark plasma sintering on the microstructure and in vitro behavior of plasma sprayed HA coatings," Biomaterials, vol. 24, no. 16, pp. 2695-2705, 2003.

[9] Y. W. Gu, K. A. Khor, and P. Cheang, "Bone-like apatite layer formation on hydroxyapatite prepared by spark plasma sintering (SPS)," Biomaterials, vol. 25, no. 18, pp. 4127-4134, 2004.

[10] S. Oh, N. Oh, M. Appleford, and J. L. Ong, "Bioceramics for tissue engineering applications-a review," American Journal of Biochemistry and Biotechnology, vol. 2, no. 2, pp. 49-56, 2006.

[11] K. Balani, Y. Chen, S. P. Harimkar, N. B. Dahotre, and A. Agarwal, "Tribological behavior of plasma-sprayed carbon nanotube-reinforced hydroxyapatite coating in physiological solution," Acta Biomaterialia, vol. 3, no. 6, pp. 944-951, 2007.

[12] Y. Chen, T. H. Zhang, C. H. Gan, and G. Yu, "Wear studies of hydroxyapatite composite coating reinforced by carbon nanotubes," Carbon, vol. 45, no. 5, pp. 998-1004, 2007. 
[13] D. Gopi, E. Shinyjoy, M. Sekar, M. Surendiran, L. Kavitha, and T. S. Sampath Kumar, "Development of carbon nanotubes reinforced hydroxyapatite composite coatings on titanium by electrodeposition method," Corrosion Science, vol. 73, pp. 321330, 2013.

[14] T. M. Sridhar, U. Kamachi Mudali, and M. Subbaiyan, "Sintering atmosphere and temperature effects on hydroxyapatite coated type 316L stainless steel," Corrosion Science, vol. 45, no. 10, pp. 2337-2359, 2003.

[15] X. H. Chen, C. S. Chen, H. N. Xiao, F. Q. Cheng, G. Zhang, and G. J. Yi, "Corrosion behavior of carbon nanotubes-Ni composite coating," Surface and Coatings Technology, vol. 191, no. 2-3, pp. 351-356, 2005.

[16] B. M. Praveen, T. V. Venkatesha, Y. Arthoba Naik, and K. Prashantha, "Corrosion studies of carbon nanotubes-Zn composite coating," Surface and Coatings Technology, vol. 201, no. 12, pp. 5836-5842, 2007.

[17] N. Ignjatović, S. Tomić, M. Dakić, M. Miljković, M. Plavšić, and D. Uskoković, "Synthesis and properties of hydroxyapatite/ poly-L-lactide composite biomaterials," Biomaterials, vol. 20, no. 9, pp. 809-816, 1999.

[18] A. Bigi, E. Boanini, S. Panzavolta, and N. Roveri, "Biomimetic growth of hydroxyapatite on gelatin films doped with sodium polyacrylate," Biomacromolecules, vol. 1, no. 4, pp. 752-756, 2000.

[19] J. D. Hartgerink, E. Beniash, and S. I. Stupp, "Self-assembly and mineralization of peptide-amphiphile nanofibers," Science, vol. 294, no. 5547, pp. 1684-1688, 2001.

[20] S. Iijima, "Helical microtubules of graphitic carbon," Nature, vol. 354, no. 6348, pp. 56-58, 1991.

[21] B.-D. Hahn, J.-M. Lee, D.-S. Park et al., "Mechanical and in vitro biological performances of hydroxyapatite-carbon nanotube composite coatings deposited on Ti by aerosol deposition," Acta Biomaterialia, vol. 5, no. 8, pp. 3205-3214, 2009.

[22] M. S. Dresselhaus and H. Dai, "Carbon nanotubes: continued innovations and challenges," MRS Bulletin, vol. 29, no. 4, pp. 237-243, 2004.

[23] A. Peigney, "Composite materials: tougher ceramics with nanotubes," Nature Materials, vol. 2, no. 1, pp. 15-16, 2003.

[24] A. Li, K. Sun, W. Dong, and D. Zhao, "Mechanical properties, microstructure and histocompatibility of MWCNTs/HAp biocomposites," Materials Letters, vol. 61, no. 8-9, pp. 1839-1844, 2007.

[25] M.-F. Yu, O. Lourie, M. J. Dyer, K. Moloni, T. F. Kelly, and R. S. Ruoff, "Strength and breaking mechanism of multiwalled carbon nanotubes under tensile load," Science, vol. 287, no. 5453, pp. 637-640, 2000.

[26] P. Avouris, "Carbon nanotube electronics," Chemical Physics, vol. 281, no. 2-3, pp. 429-445, 2002.

[27] Y. Di, X. Yang, W. Lei et al., "Surface modification of CNTcathodes by an acid-erosion process," Nanotechnology, vol. 18, no. 50, Article ID 505701, pp. 1-5, 2007.

[28] Q. Li, J. Liu, and S. Xu, "Progress in research on carbon nanotubes reinforced cementitious composites," Advances in Materials Science and Engineering, vol. 2015, Article ID 307435, 16 pages, 2015.

[29] Y. Usui, K. Aoki, N. Narita et al., "Carbon nanotubes with high bone-tissue compatibility and bone-formation acceleration effects," Small, vol. 4, no. 2, pp. 240-246, 2008.

[30] M. Kalbacova, M. Kalbac, L. Dunsch, and U. Hempel, "Influence of single-walled carbon nanotube films on metabolic activity and adherence of human osteoblasts," Carbon, vol. 45, no. 11, pp. 2266-2272, 2007.

[31] D. Lahiri, A. P. Benaduce, F. Rouzaud et al., "Wear behavior and in vitro cytotoxicity of wear debris generated from hydroxyapatite-carbon nanotube composite coating," Journal of Biomedical Materials Research A, vol. 96, no. 1, pp. 1-12, 2011.

[32] M. Matsuoka, T. Akasaka, Y. Totsuka, and F. Watari, "Strong adhesion of Saos-2 cells to multi-walled carbon nanotubes," Materials Science and Engineering B: Solid-State Materials for Advanced Technology, vol. 173, no. 1-3, pp. 182-186, 2010.

[33] T. Akasaka, A. Yokoyama, M. Matsuoka, T. Hashimoto, and F. Watari, "Thin films of single-walled carbon nanotubes promote human osteoblastic cells (Saos-2) proliferation in low serum concentrations," Materials Science and Engineering C, vol. 30, no. 3, pp. 391-399, 2010.

[34] A. Agarwal, S. R. Bakshi, and D. Lahiri, Carbon Nanotubes: Reinforced Metal Matrix Composites, CRC Press, Boca Raton, Fla, USA, 2010.

[35] S. C. Tjong, Carbon Nanotube Reinforced Composites: Metal and Ceramic Matrices, Wiley-VCH, Weinheim, Germany, 2009.

[36] V. Mittal, Polymer Nanotube Nanocomposites: Synthesis, Properties and Applications, Wiley Publishers, Hoboken, NJ, USA, 2010.

[37] C. S. Ciobanu, F. Massuyeau, L. V. Constantin, and D. Predoi, "Structural and physical properties of antibacterial Ag-doped nano-hydroxyapatite synthesized at $100^{\circ} \mathrm{C}$," Nanoscale Research Letters, vol. 6, article 613, no. 1, 2011.

[38] C. S. Ciobanu, S. L. Iconaru, P. Le Coustumer, L. V. Constantin, and D. Predoi, "Antibacterial activity of silver-doped hydroxyapatite nanoparticles against gram-positive and gram-negative bacteria," Nanoscale Research Letters, vol. 7, no. 1, article 324, 2012.

[39] I. Cacciotti, A. Bianco, M. Lombardi, and L. Montanaro, "Mgsubstituted hydroxyapatite nanopowders: synthesis, thermal stability and sintering behaviour," Journal of the European Ceramic Society, vol. 29, no. 14, pp. 2969-2978, 2009.

[40] L. Wu, C. Man, H. Wang et al., "PEGylated multi-walled carbon nanotubes for encapsulation and sustained release of oxaliplatin," Pharmaceutical Research, vol. 30, no. 2, pp. 412423, 2013.

[41] Y.-G. Han, J. Xu, Z.-G. Li, G.-G. Ren, and Z. Yang, "In vitro toxicity of multi-walled carbon nanotubes in C6 rat glioma cells," NeuroToxicology, vol. 33, no. 5, pp. 1128-1134, 2012.

[42] A. Dinischiotu, L. Stanca, D. Gradinaru, S. N. Petrache, M. Radu, and A. I. Serban, "Lipid peroxidation due to in vitro and in vivo exposure of biological samples to nanoparticles," Methods in Molecular Biology, vol. 1028, pp. 155-164, 2013.

[43] M. M. Bradford, "A rapid and sensitive method for the quantitation of microgram quantities of protein utilizing the principle of protein-dye binding," Analytical Biochemistry, vol. 72, no. 1-2, pp. 248-254, 1976.

[44] E. Battaut, "Particle sizes and their statistics from Debye-Sherrer lines," in International Tables for X-Ray Crystallography, C. H. MacGillavary and G. D. Riecks, Eds., pp. 318-323, Kynocts Press, Boston, Mass, USA, 1962.

[45] H. Najafi, Z. A. Nemati, and Z. Sadeghian, "Inclusion of carbon nanotubes in a hydroxyapatite sol-gel matrix," Ceramics International, vol. 35, no. 7, pp. 2987-2991, 2009.

[46] C. S. Ciobanu, C. L. Popa, and D. Predoi, "Sm:HAp nanopowders present antibacterial activity against Enterococcus faecalis," Journal of Nanomaterials, vol. 2014, Article ID 780686, 9 pages, 2014. 
[47] M. Markovic, B. O. Fowler, and M. S. Tung, "Preparation and comprehensive characterization of a calcium hydroxyapatite reference material," Journal of Research of the National Institute of Standards and Technology, vol. 109, no. 6, pp. 553-568, 2004.

[48] L. Yang, W. Z. Wei, X. H. Gao, J. J. Xia, and H. Tao, "A new antibody immobilization strategy based on electrodeposition of nanometer-sized hydroxyapatite for label-free capacitive immunosensor," Talanta, vol. 68, no. 1, pp. 40-46, 2005.

[49] D. Pan, Y. Wang, Z. Chen, T. Yin, and W. Qin, "Fabrication and characterization of carbon nanotube-hydroxyapatite nanocomposite: application to anodic stripping yoltammetric determination of cadmium," Electroanalysis, vol. 21, no. 8, pp. 944-952, 2009.

[50] C. S. Ciobanu, E. Andronescu, B. S. Vasile, C. M. Valsangiacom, R. V. Ghita, and D. Predoi, "Looking for new synthesis of hydroxyapatite doped with europium," Journal of Optoelectronics and Advanced Materials, vol. 4, pp. 1515-1519, 2010.

[51] X. Bai, K. More, C. M. Rouleau, and A. Rabiei, "Functionally graded hydroxyapatite coatings doped with antibacterial components," Acta Biomaterialia, vol. 6, no. 6, pp. 2264-2273, 2010.

[52] L. Niu, H. Kua, and D. H. C. Chua, "Bonelike apatite formation utilizing carbon nanotubes as template," Langmuir, vol. 26, no. 6, pp. 4069-4073, 2010.

[53] M. Krishna Kumar, A. Leela Mohana Reddy, and S. Ramaprab$\mathrm{hu}$, "Exfoliated single-walled carbon nanotube-based hydrogen sensor," Sensors and Actuators, B: Chemical, vol. 130, no. 2, pp. 653-660, 2008.

[54] R. Wahab, S. G. Ansari, Y. S. Kim, T. R. Mohanty, I. H. Hwang, and H.-S. Shin, "Immobilization of DNA on nano hydroxyapatite and their interaction with carbon nanotubes," Synthetic Metals, vol. 159, no. 3-4, pp. 238-245, 2009.

[55] A. M. Rao, E. Richter, S. Bandow et al., "Diameter-selective Raman scattering from vibrational modes in carbon nanotubes," Science, vol. 275, no. 5297, pp. 187-190, 1997.

[56] Q. Liu, W. Liu, Z.-M. Cui, W.-G. Song, and L.-J. Wan, "Synthesis and characterization of 3D double branched $\mathrm{K}$ junction carbon nanotubes and nanorods," Carbon, vol. 45, no. 2, pp. 268-273, 2007.

[57] J. L. Xu, K. A. Khor, J. J. Sui, and W. N. Chen, "Preparation and characterization of a novel hydroxyapatite/carbon nanotubes composite and its interaction with osteoblast-like cells," Materials Science and Engineering C, vol. 29, no. 1, pp. 44-49, 2009.

[58] G. M. Neelgund, K. Olurode, Z. Luo, and A. Oki, "A simple and rapid method to graft hydroxyapatite on carbon nanotubes," Materials Science and Engineering C, vol. 31, no. 7, pp. 1477-1481, 2011.

[59] W. Zheng, Q. Li, L. Su, Y. Yan, J. Zhang, and L. Mao, "Direct electrochemistry of multi-copper oxidases at carbon nanotubes noncovalently functionalized with cellulose derivatives," Electroanalysis, vol. 18, no. 6, pp. 587-594, 2006.

[60] H. Patel and S. Kwon, "Multi-walled carbon nanotube-induced inflammatory response and oxidative stress in a dynamic cell growth environment," Journal of Biological Engineering, vol. 6, article 22, 2012. 

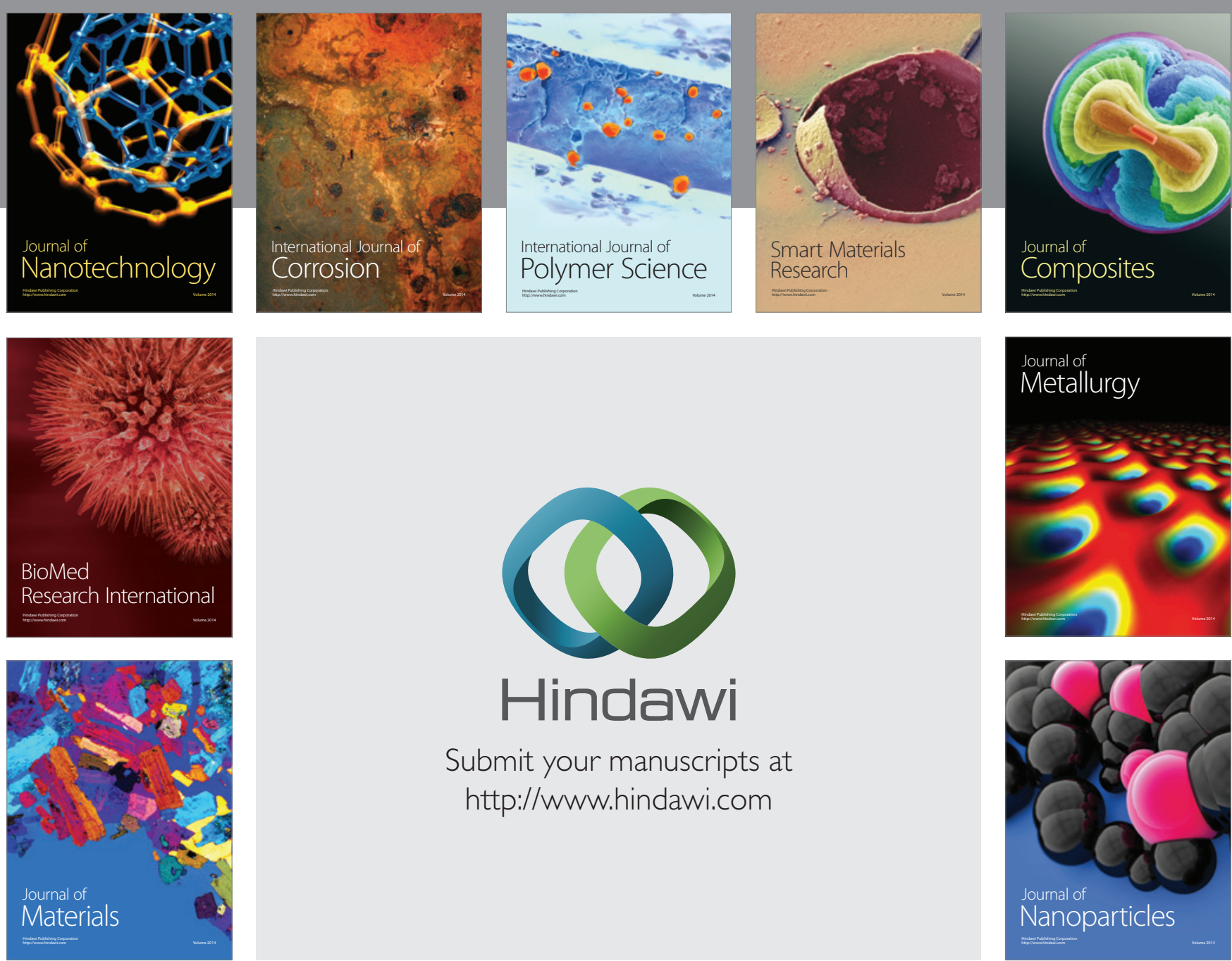

\section{Hindawi}

Submit your manuscripts at

http://www.hindawi.com

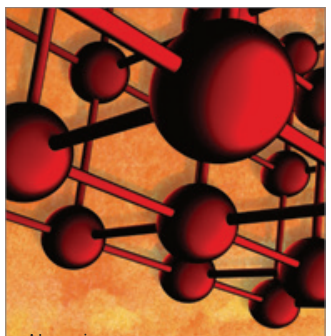

Materials Science and Engineering
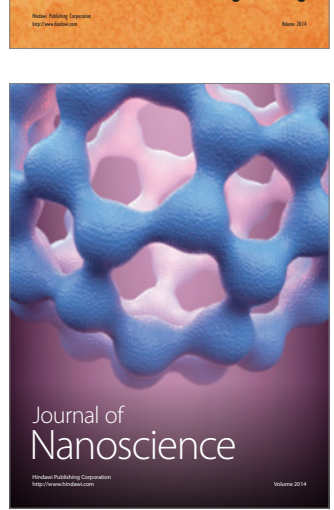
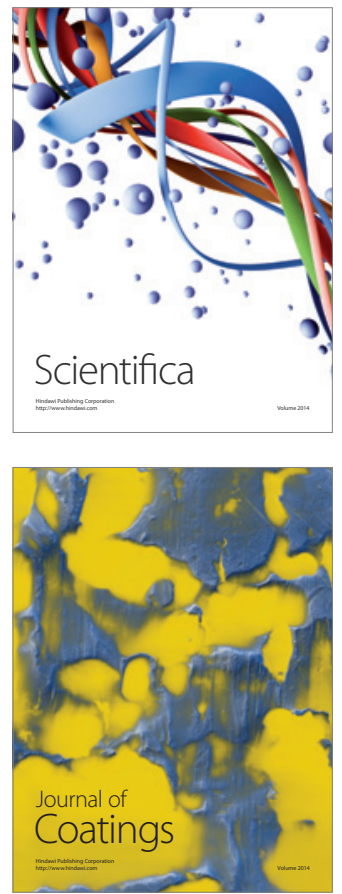
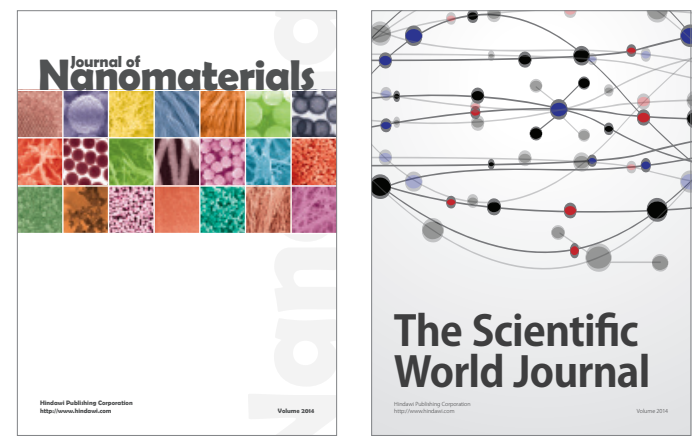

The Scientific World Journal
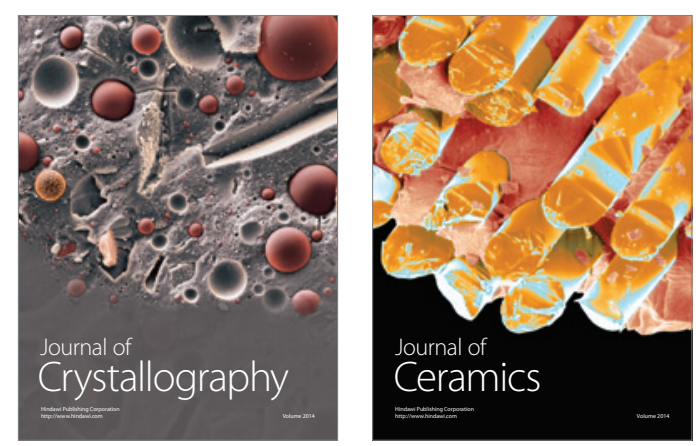
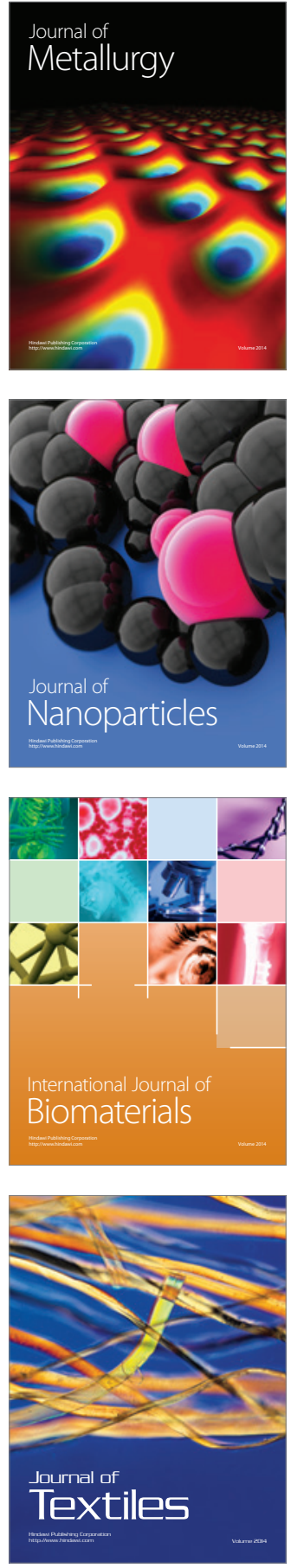